\title{
Impact of soil puddling intensity on the root system architecture of rice (Oryza sativa $\mathrm{L}$.) seedlings
}

Huan Fang, ${ }^{\mathrm{a}, \mathrm{b}}$, Hui Rong ${ }^{\mathrm{a}, \mathrm{b}}$, Paul D. Hallett ${ }^{\mathrm{c}}$, Sacha J. Mooney ${ }^{\mathrm{d}}$, Weijian Zhang ${ }^{\mathrm{e}}$, Hu Zhou $^{\mathrm{a}, \mathrm{c}, \mathrm{d}^{*}}$, Xinhua Peng ${ }^{\mathrm{a} *}$

${ }^{a}$ State Key Laboratory of Soil and Sustainable Agriculture, Institute of Soil Science, Chinese Academy of Sciences. No. 71 East Beijing Road, Nanjing 210008, China

${ }^{\mathrm{b}}$ University of Chinese Academy of Sciences, No.19A Yuquan Road, Beijing 100049, China

${ }^{c}$ School of Biological Sciences, University of Aberdeen, Aberdeen AB24 3UU, United Kingdom

${ }^{d}$ Division of Agricultural and Environmental Sciences, School of Biosciences, University of Nottingham, Sutton Bonington Campus, Loughborough, Leicestershire LE12 5RD, United Kingdom

e Institute of Crop Sciences, Chinese Academy of Agricultural Sciences, Beijing 100081, China

* Corresponding author

$\mathrm{Hu}$ Zhou

Phone: $86(25) 86881221$

Fax: $86(25) 86881000$

E-mail: zhouhu@issas.ac.cn

and

Xinhua Peng

Phone: $86(25) 86881198$

Fax: $86(25) 86881000$

E-mail: xhpeng@,issas.ac.cn 


\section{Abstract}

2 Puddling of rice paddies is undertaken to create a soft soil bed for easy transplanting

3 of rice seedlings, to control weeds and reduce water and nutrient leaching. There is a

4 drive for less intense puddling because of its physical disturbance of soil, energy

5 inputs and labour requirements, which may produce different soil physical conditions

6 for root growth. The objective of this study was to investigate the influence of

7 puddling intensity on soil structure and the subsequent impact on the growth of rice

8 seedling roots. Three treatments with different puddling intensities were established:

9 (1) No puddling; (2) Low and (3) High intensity puddling. The rice genotype,

10 Nipponbare was grown in soil columns for 18 days. Soil bulk density, aggregate size

11 distribution and three-dimensional (3D) macropore structure were measured.

12 Two-dimensional root traits were determined by WinRhizo and 3D root traits were

13 determined by X-ray Computed Tomography (CT). Our results show the percentage

14 of large macroaggregates $(>2 \mathrm{~mm})$ decreased by $69.6 \%(P<0.05)$ for low intensity

15 puddling and by $95.7 \%(P<0.05)$ for high intensity puddling compared with that of

16 no puddling. The macroporosity $(>0.03 \mathrm{~mm})$ of no puddling was 2.3 times greater

17 than low intensity puddling and 3.5 times greater than high intensity puddling. The

18 total root lengths of no and low intensity puddling were 1.56-1.86 times greater than

19 that of high intensity puddling. Large roots, including radicle and crown roots, were

20 the same length regardless of puddling intensity. Our study demonstrates that

21 intensive puddling can degrade soil structure, which consequently limits rice root

22 growth.

24 Keywords: Puddling; Pore structure; Root architecture; Soil structure; X-ray 
computed tomography

\section{1. Introduction}

27 Puddling is the most common tillage practice for lowland rice (Oryza sativa L.)

28 cultivation in Asian countries (Bouman et al., 2007; Eickhorst and Tippkötter, 2009).

29 Puddling breaks down and disperses soil aggregates into micro-aggregates and

30 individual particles (Zhang et al., 2016), which helps with the creation of a soft soil

31 bed for easy transplanting of rice seedlings, weed control and the reduction of water

32 and nutrients leaching (Bouman et al., 2007; Kirchhof et al., 2011; Sharma and De

33 Datta, 1985). Societal change in China has resulted in a rapid decrease in puddling

34 intensity (Wang et al., 2017) as more large-scale family farms have emerged from the

35 land-use right transfer from small-scale farms (Liu, 2018). Unlike the small-scale

36 farmers who keep puddling the paddy fields for rice seedlings, larger scale operations

37 often reduce puddling intensity to save on labour and energy costs, and to prepare

38 fields rapidly to maximise the length of growing seasons. Some farmers have gone as

39 far as implementing reduced and zero tillage in rice cultivation to achieve this (Wang

40 et al., 2017). However, there is a lack of knowledge concerning how these drastic

41 changes in preparing soil for rice paddy production affect the interactions between

42 rice and soils. Yields can be maintained or sometimes improved with less intense

43 puddling (Mohanty et al., 2004), which counters the common perception of many

44 farmers (Wang et al., 2017).

45 Puddling has a significant effect on soil structure that may influence root growth.

46 Previous studies have shown that the intensity of puddling influences the physical

47 properties of paddy soil such as aggregate stability, bulk density, pore size distribution,

48 penetration resistance, water retention and hydraulic conductivity (Mohanty et al., 
2004; Mousavi et al., 2009; Rezaei et al., 2012; Yoshida and Adachi, 2002). These

50 changes to soil physical properties due to puddling intensity likely affect rice root

51 growth (Bengough et al., 2011; Kirchhof et al., 2000; Valentine et al., 2012; White

52 and Kirkegaard, 2010) and yields, often contrary to what farmers may expect

53 (Mohanty et al., 2004). Sharma and De Datta (1985) reported that intense puddling

54 impeded root development and therefore led to a decline in yield. Other researchers

55 have demonstrated that puddling can increase weeding efficiency and provide a better

56 environment for nutrient uptake, leading to increased grain yield (Arora et al., 2006;

57 Mohanty and Painuli, 2003; Mohanty et al., 2004; Singh et al., 2013; Subramanyam et 58 al., 2007).

59 Both soil pore size distribution and aggregation are greatly affected by puddling,

60 which can have a direct impact on crop yield due to the physical impacts on root

61 growth and resource capture (Cairns et al., 2004). Much work in this area has focused

62 on soil aggregates or bulk parameters such as bulk density and hydraulic conductivity

63 (Rezaei et al., 2012), but a detailed analysis concerning the impact on the soil pore

64 system has been largely ignored. The soil pore network has a profound influence on

65 root growth, providing a continuous network of appropriately sized soil pores that

66 provide growth channels for roots (Tracy et al., 2012b). In a previous study, we found

67 that different pore structures had a large influence on root elongation and morphology,

68 even if soil bulk densities were identical (Fang et al., 2018). This study explored

69 impacts of hydraulic stress history, with X-ray Computed Tomography (CT) imaging

70 using to quantify the $3 \mathrm{D}$ pore structure. Scope exists to further this noninvasive

71 approach to explore puddling intensity impacts, coupled with visualization of the 3D

72 root system, as applied to a wide range of crop species (Helliwell et al., 2013). 
X-ray CT imaging provides micron resolution, 3D images of the interaction

74 between soil structure and root system architecture. Compared to the destructive

75 methods like root washing, CT imaging can examine undisturbed 3D root architecture,

76 including branching characteristics and extension rate, which are inherently linked to

77 conditions within the soil matrix (Tracy et al., 2010). At the same time, it provides

78 information on soil pore structure and its capacity to serve as growth pathways for

79 roots (Helliwell et al., 2017). The application of X-ray CT also has a number of

80 disadvantages including the trade-off between spatial resolution and sample size

81 (Zappala et al., 2013), which can limit the portion of the root system that is observable

82 or the size of plants. Scans of $100-150 \mathrm{~mm}$ diameter samples are typically limited to

83 about 50-80 $\mu \mathrm{m}$ resolution, so only the larger roots (e.g., radicle and crown roots) of

84 cereal plants are clearly visible. With root washing, on the other hand, information

85 concerning the radicle, crown roots and lateral roots can be collected, but the spatial

86 arrangement of the roots is disturbed. Therefore, combining X-ray CT and root

87 washing methods offers a better understanding of root system architecture (Tracy et

88 al., 2012a).

89 The aim of this study was to explore the effect of different puddling intensities

90 on soil physical properties and their influence on rice root development. Soil physical

91 conditions were characterized by aggregate size distribution, bulk density and a

92 detailed analysis of 3D pore structure by X-ray CT. Root system architecture was

93 studied using X-ray CT imaging and root washing methods. Our hypothesis was that

94 the destruction of soil aggregates and pore structure by puddling will decrease root

95 length and branching. We also anticipated that a greater intensity of puddling will

96 increase mechanical impedance. Our hypothesis is counter-intuitive to the common 
97 belief that greater puddling intensity produces better rice root growth. With new data,

98 including easily accessible 3D visual images of root interactions with soil structure, a

99 primary aim of this study is to demonstrate the benefits of less intense puddling in rice

100 production. It addresses current changes in farming practices in China, as well as

101 concerns about the impact of intense puddling on soil sustainability.

102

103 2. Materials and methods

104 2.1. Experimental design

105 Paddy soil (4.7\% sand, $67.2 \%$ silt and $28.1 \%$ clay) was obtained from the

106 Institute of Red Soil, Jinxian County, Jiangxi Province, China (28 $\left.37^{\prime} \mathrm{N}, 116^{\circ} 26^{\prime} \mathrm{E}\right)$.

107 The $\mathrm{pH}$ of the soil was 5.3. The soil organic carbon content was $24.8 \mathrm{~g} \mathrm{~kg}^{-1}$. The total

108 nitrogen $(\mathrm{N})$, phosphorus $(\mathrm{P})$ and potassium $(\mathrm{K})$ content of the soil were $2.60 \mathrm{~g} \mathrm{~kg}^{-1}$,

$1091.28 \mathrm{~g} \mathrm{~kg}^{-1}, 12.36 \mathrm{~g} \mathrm{~kg}^{-1}$, respectively. The soil was air-dried and passed through a 5

$110 \mathrm{~mm}$ sieve to retain some its inherent structure, whilst allowing for packing into small

111 soil columns compatible with X-Ray CT scanning.

112 Soil treatments with different puddling intensities were formed in polyvinyl

113 chloride (PVC) columns (inner diameter $48 \mathrm{~mm}$, height $80 \mathrm{~mm}$ ). To retain soil during

114 the puddling process, two columns were taped together so that soil would not splash

115 outside of the sample. Each stacked column had $200 \mathrm{~g}$ of soil loosely packed inside,

116 with soil surface below the middle of the upper column to avoid soil falling out during

117 stirring. The repacked soils were then saturated by placing the columns in a container

118 and submerging in water for $72 \mathrm{~h}$. They were then mixed with an electric mixer

119 equipped with a $1000 \mathrm{~W}$ motor and two mixing blades. The rotating speed was 200

120 rpm. Different puddling intensities were simulated by changing stirring time, which 
121 was similar to puddling multiple times in the field. Three treatments with different

122 puddling intensities were established: (1) no puddling; (2) low intensity puddling, 200

$123 \mathrm{rpm}$ for $2 \mathrm{~min}$; and (3) high intensity puddling, $200 \mathrm{rpm}$ for $8 \mathrm{~min}$. After stirring, soils

124 were equilibrated to $-0.5 \mathrm{kPa}$ in a sand table to allow the puddled soil to settle and

125 consolidate. Once equilibrated, the upper columns and the soil within them were

126 removed carefully, with the bottom columns retained for the experiment. There were 9

127 columns produced for each treatment, split into 6 replicates used to grow rice and the

128 other 3 replicates for the measurement of soil aggregate size distribution. The rice

129 (Oryza sativa) genotype, Nipponbare, was used in this study. Rice seeds were

130 germinated on moist filter paper at $30{ }^{\circ} \mathrm{C}$ for 48 hours before being planted at $3 \mathrm{~mm}$

131 below the soil surface. All the columns were placed in a large container and kept

132 flooded during the growing period. Plants were grown in a controlled greenhouse with

133 day/night temperatures of $28 / 26^{\circ} \mathrm{C}$, a humidity of $60 \%$ and an $11 \mathrm{~h}$ photoperiod. The

134 rice plants were grown for 18 days as the soil sample size required for X-Ray CT

135 scanning restricted a longer growth period without edge affects adversely influencing

136 root morphology. Soil bulk density was determined after rice harvest by collecting all

137 the soils in the column and oven-drying at $105^{\circ} \mathrm{C}$.

\section{2.2. Aggregate size distribution}

139 The aggregate size distribution after simulated puddling was determined using a 140 sieving method modified from Elliott (1986). Briefly, a series of sieves were used to 141 obtain four aggregate size fractions: 1) $>2 \mathrm{~mm}$ (large macroaggregates); 2) 0.25-2 $142 \mathrm{~mm}$ (small macroaggregates); 3) 0.053-0.25 mm (microaggregates); 4) $<0.053 \mathrm{~mm}$ 143 (silt and clay fractions). The sieves were manually moved up and down by about $3 \mathrm{~cm}$ 144 a total of 50 times during $2 \mathrm{~min}$. The aggregates remaining on each sieve were 
145 oven-dried at $105{ }^{\circ} \mathrm{C}$ until they reached a constant weight. The mean weight diameter

146 (MWD) of the aggregates was calculated as follows:

$147 \quad \mathrm{MWD}=\sum_{i=1}^{n+1} \frac{r_{i-1}+r_{i}}{2} \times m_{i}$

148 where $r_{\mathrm{i}}$ is the aperture size of the $i^{\text {th }}$ sieve $(\mathrm{mm}), m_{\mathrm{i}}$ is the mass proportion of the

149 aggregate fraction remaining on the $i^{\text {th }}$ sieve, and $n$ is the number of sieves.

150 2.3. X-ray CT scanning and image processing

151 Soil columns were scanned using a Phoenix Nanotom X-ray $\mu$-CT (GE, Sensing

152 and Inspection Technologies, GmbH, Wunstorf, Germany) at the Institute of Soil

153 Science, Chinese Academy of Sciences. The voltage was $110 \mathrm{kV}$, the current was 110

$154 \mu \mathrm{A}$, the exposure time was $1250 \mathrm{~ms}$, and a $0.1 \mathrm{~mm} \mathrm{Cu}$ filter was used to reduce the

155 beam hardening effect. A total of 1200 projection images were collected during the

156 rotation of each sample. To improve image quality, each projection image was

157 collected three times, with the first projection image skipped and the average of the

158 last two projections saved as one projection image. The voxel size was $0.03 \mathrm{~mm}$.

159 Slices were reconstructed with Datos $\mid \times 2.0$ software using the filtered back-projection

160 algorithm. The slices were saved as 16-bit tiff format.

161 X-ray CT image data analysis is extremely time consuming, so only three of the

162 six replicates of each treatment were randomly selected and scanned at day 0 and day

163 18. Soil columns were placed on dry sands for 1 hour before scanning to drain the soil

164 water in the macropores because a high proportion of water-filled pores can impact

165 image quality, especially for root segmentation (Zappala et al., 2013). CT images

166 from day 0 were used to analyze soil pore structure using imageJ (Version $1.50 \mathrm{e}$ ). The

167 image stack of each sample was cropped to a region of interest (ROI) of $700 \times 700$ 
168 pixels $(21 \times 21 \mathrm{~mm})$ and a depth of 700 continuous slices $(21 \mathrm{~mm})$. Cropping the

169 images and reducing the size of the stacks was necessary to avoid artefacts detected at

170 the edges or top and bottom of columns such as those caused by use of a cone X-ray

171 beam or beam hardening (Deurer et al. 2009; Mooney et al. 2006). Images were

172 segmented using a 'Default' thresholding method, a variation on the 'IsoData' method

173 where the average of the object and background image are used to compute the

174 threshold. Porosity and pore size distribution were computed using the 'thickness'

175 plugin in ImageJ. This approach fits the largest sphere inside the 3D pore space that

176 touches the bordering soil matrix and then measures the sphere diameter, which is

177 regarded as the corresponding "pore size". The global connectivity $(\Gamma)$ of soil pore

178 networks can be defined as follows:

179

$$
\Gamma=\frac{\sum_{i=0}^{n}\left(V_{i}^{2}\right)}{\left(\sum_{i=0}^{n} V_{i}\right)^{2}}
$$

180 The $\Gamma$ measures the probability of pores belonging to the same pore. A $\Gamma$ equal to

1811 indicates that all pores are connected in one percolating pore, whereas a $\Gamma$ close to 0

182 indicates that pores with similar size are scattered (Hovadik and Larue, 2007). $V_{i}$ is

183 the volume of the $i^{\text {th }}$ macropore.

184 CT images from day 18 were analysed to quantify root architecture. Root 185 systems were segmented using the "Region Growing" tool in VG StudioMax 2.1

186 software. The root length, volume, surface area, mean diameter and tortuosity of root 187 path (the ratio of actual path length divided by the shortest possible path) were 188 measured on the extracted root system. The root volume and surface area were 189 obtained from VG StudioMax 2.1. The root length and the tortuosity of root path were 190 obtained using 'skeleton' plugin of ImageJ. The mean diameter was computed using 191 the 'thickness' plugin in imageJ. 
After CT scanning, roots were carefully washed from the soil. Roots with soil

194 were placed on a sieve (aperture size $0.5 \mathrm{~mm}$ ) and carefully washed with tap water to

195 remove soil particulate material. All the soil material in the column was collected and

196 oven-dried at $105^{\circ}$ Cto determine soil bulk density. Root samples from each core were

197 placed in a plexiglas tray $(100$ by $100 \mathrm{~mm})$ containing a 4 to $6 \mathrm{~mm}$ deep layer of

198 water and spread out with plastic tweezers to minimize root overlapping. Roots were

199 scanned using an Expression 10000XL scanner (Epson, Suwa, Japan) and grayscale

200 images (800 DPI) of roots were obtained. Based on manual measurement, a threshold

201 diameter of $0.2 \mathrm{~mm}$ was chosen to separate larger roots (including radical and crown

202 roots) and lateral roots. Total root length, root surface area, root volume, average

203 diameter, and tip numbers were determined using WinRhizo (Version 2013e) (Regent

204 Instrument Canada Inc.).

205 2.5. Statistical analysis

206 Data were checked for normality with probability plots. One-way ANOVA and 207 post hoc analysis were conducted by the Fisher's protected least significant difference 208 (LSD) procedure with SPSS 24.0 to evaluate for significant differences between 209 treatments $(P<0.05)$.

\section{3. Results}

\section{3.1. Puddling intensity effect on aggregate size distribution and bulk density}

212 The impact of puddling intensity on soil aggregate size distribution is shown in

213 Table 1. Puddling had significant impacts on disrupting macroaggregates $(>0.25 \mathrm{~mm})$

$214(P<0.05)$ and producing microaggregates $(<0.25 \mathrm{~mm})(P<0.05)$. The percentage of 
215 aggregates $>2 \mathrm{~mm}$ with no puddling was 3.4 and 20.1 times greater than for low and

216 high puddling intensity, respectively $(P<0.05)$. The percentage of $<0.053 \mathrm{~mm}$ 217 aggregates following no puddling was $45.8 \%$ and $54.9 \%$ less than that of low and

218 high puddling intensity, respectively $(P<0.05)$. The MWD for no puddling was 2.1

219 and 3.5 times greater than that of low and high puddling intensity, respectively $(P<$ 220 0.05). Puddling increased bulk density by $10.6 \%$ for low intensity and $14.1 \%$ for high

221 intensity compared to no puddling $(P<0.05)$ (Table 1$)$.

222

223

224

225

\subsection{Puddling intensity effect on macropores}

Representative longitudinal cross-section images of the different treatments are shown in Fig. 1. Puddling clearly disrupted the pore structure, resulting in lower bulk porosities (Table 1) and more small pores (Fig. 1). Compared to no puddling, the number of large pores decreased with increasing puddling intensity. The connected inter-aggregate pores were destroyed by puddling, producing isolated vesicular pores after low intensity puddling. After high intensity puddling, most of the larger macropores had disappeared (Figs. $1 \& 2$ ). The circular pores following puddling were not connected at the image resolution in this study (Fig. 1). The trends observed in the $2 \mathrm{D}$ images were also shown in the representative 3D soil structure (Fig. 2).

Quantitative analyses of the 3D macropore system indicated puddling decreased soil macroporosity and macropore size, with the impacts being greater for high intensity than low intensity puddling (Fig. 3). The cumulative macroporosity with no puddling was 2.3 time greater than for low intensity puddling and 3.5 times greater than for high intensity puddling (Fig. 3b). Over a broad range of pores size intervals (0.03-2.4 $\mathrm{mm})$ no puddling had much greater porosity than the two puddled treatments (Fig. 3a). These results confirmed our hypothesis that puddling destroys 
239 soil macropores. From the cumulative pore size distribution, low intensity and high

240 intensity puddling started to deviate from each other at $>0.6 \mathrm{~mm}$ pores, reaching a

241 difference of 3.9 times in total porosity between $0.6 \mathrm{~mm}$ and $2.4 \mathrm{~mm}$ pore sizes (Fig.

$2423 b)$. The global connectivity $(\Gamma)$ of macropores decreased with increased puddling

243 intensity (Table 1). The pore connectivity of high intensity puddling was significantly

244 less than that of no puddling $(P<0.05)$ (Table 1).

245 3.3. Puddling intensity effect on root traits

246 In 3D root images from X-ray CT imaging, information including the spatial 247 position and 3D architecture of the roots was obtained (Fig. 4). Due to the limitation

248 of image resolution, the CT imaging technique only revealed larger roots including 249 radicle and crown roots, with smaller lateral roots not detectable. Quantitative 250 analysis of CT images found no significant difference in the traits of detected roots,

251 including root length, diameter, surface area, volume, and tortuosity among the 252 treatments (Table 2).

253 Most roots could be detected following washing from the soil (Fig. 5) and 254 analysis with WinRhizo, with very good agreement of the root length of roots $>0.2$ $255 \mathrm{~mm}$ between this approach and X-Ray CT imaging (Tables $2 \& 3$ ). Other root traits 256 such as volume and surface area were much greater by root washing analysis. Larger 257 roots $(>0.2 \mathrm{~mm})$ quantified by root washing had similar traits regardless of puddling 258 intensity $(P>0.05)$ (Table 3$)$. Smaller lateral roots $(<0.2 \mathrm{~mm})$ decreased with 259 increasing puddling intensity (Table 3), with 1.55 times greater total root length for no 260 puddling versus high intensity puddling. The surface area of small lateral roots for no 261 puddling was 1.60 times greater than that of the high intensity puddling $(P<0.05)$. 262 Small lateral roots had a similar number of tips and volume regardless of puddling 
intensity $(P>0.05)$ (Table 3$)$.

264 For the entire root system, the total root length with no puddling was 1.43 times

265 greater than that with high intensity puddling $(P<0.05)$. The average root diameters

266 of the low and high intensity puddling were $12.2 \%$ and $16.8 \%$ greater than that of no

267 puddling $(P<0.05)$ (Table 3$)$, respectively.

\section{Discussion}

Puddling intensity has a large impact on soil physical structure that affects the

271 root architecture of rice. Despite mechanically disrupting inherent macro-aggregates

272 to micro-aggregates with an intention to 'loosen' the soil, pluviation of the soil and

273 subsequent consolidation produces the counter-intuitive response with soil bulk

274 density increasing alongside increasing puddling intensity (Table 1). Puddling

275 destroyed macro-aggregates to micro-aggregates or even dispersed soil particles,

276 resulting in decreased aggregate sizes (Table 1). This effect was more pronounced

277 when the puddling intensity was increased by a longer puddling time (Table 1), as

278 reported in previous studies (Kirchhof et al., 2000; Deng et al., 2014; Zhang et al., 279 2016).

280 Our study provided unprecedented visualization of the impact of puddling

281 intensity on the resulting pore structure, facilitated through X-ray CT imaging.

282 Puddling intensity not only decreased soil macroporosity $(>0.03 \mathrm{~mm})$, producing

283 smaller pores with less total macropore volume (Fig. 3), but also altered pore

284 morphology (Figs. $1 \& 2$ ) and decreased pore connectivity (Table 1). This supports

285 findings by Lal and Shukla (2004) and Chauhan et al. (2012) who also pointed out 286 puddling caused the loss of both inter- and intra- aggregate macropores. Due to the 
287 difficulty of sampling soil after puddling (Sharma and De Datta, 1985), few studies

288 have sought to directly investigate the soil pore structure after puddling. An advantage

289 of X-ray CT imaging is the ability to investigate 3D pore morphology, including 290 shape and connectivity besides porosity. The decreased macroporosity and 291 connectivity in the puddled soil is likely to reduce gas exchange and water 292 conductivity, and impact plant root growth (Sharma and De Datta, 1985).

293 The greater bulk density with increasing puddling intensity agrees with some 294 earlier experiments (Kukal and Aggarwal, 2003; Lima et al., 2009), but some other 295 studies have found the converse in that puddling decreased soil bulk density (Rezaei 296 et al., 2012; Zhang et al., 2016). This discrepancy mainly results from the time of 297 sampling. Kukal and Aggarwal (2003) and Lime et al. (2009) sampled after harvest, 298 whereas in the other two studies (Rezaei et al., 2012; Zhang et al., 2016) soil bulk 299 density was measured shortly after puddling. Zhang et al. (2013) found that soil bulk 300 density increased with wetting and drying cycles over the course of a rice season. One 301 objective of puddling is to create a soft soil bed for easy rice transplanting (Bouma et 302 al., 2007; Kirchhof et al., 2011) so that the paddy soil bulk density is quite low and 303 soil strength is weak after puddling. However, the dispersing of soil aggregates and 304 particles is at a cost of losing macropores (Figs. 1 \& 2) after puddling, resulting in a 305 higher bulk density developing following wetting and drying cycles (Table 1). 306 Adopting less intensive puddling, as is increasingly common with societal changes in 307 China, may lead to more favourable soil physical conditions for root growth.

308 We found only minimal impact of puddling intensity on large root (radical and 309 crown roots) architecture for the 18 day old rice plants studied (Table 2). However, 310 the increased root length and decreased root diameter observed with decreasing 
311 puddling intensity follows a favourable trajectory. Root system architecture is

312 strongly dependent on genotype, but soil conditions can have an even greater impact

313 (Bengough et al., 2011). Soil structure determines the balance of axial and radial

314 pressures on the individual root tip, and hence the root elongation response

315 (Bengough, 2012). Lipiec et al. (2012) demonstrated root elongation and anatomy to

316 be quite plastic in response to the local soil environment around the roots. During

317 elongation, the root tip is pushed forward into the soil and has to overcome the

318 mechanical resistance of the soil (Hodge et al., 2009). Kolb et al. (2017) reported that

319 roots respond differently to different size class of soil aggregates/particles depending

320 on whether the root can deform or dislodge the aggregates/particles. If not, roots may

321 change their trajectory to exploit looser soil areas nearby or grow through macropores

322 (Colombi et al., 2017). Roots that are able to penetrate the soil reorganize particles,

323 which in turn modifies the distribution of pores and the local soil packing fraction

324 which affects further root growth (Whiteley and Dexter, 1984). Despite large

325 differences in soil structure caused by puddling intensity in our study, root system

326 architecture of $>0.2 \mathrm{~mm}$ roots was not affected (Tables $2 \& 3$ ), likely due to the low

327 penetration resistance of the flooded soil (Kukal and Aggarwal, 2003). Lateral roots

$328(<0.2 \mathrm{~mm})$, however, were suppressed with increasing puddling intensity (Table 3$)$.

329 For no puddling, they were longer and more tortuous than those of the puddled soils

330 (Fig. 5, Table 3). Two processes could drive these differences. The lateral roots may

331 be suppressed under poor aeration conditions (Ben-Noach and Friedman, 2018). The

332 intensive puddling caused smaller and more disconnected macropores (Figs. 1 \& 2),

333 which strongly limits soil air diffusion. On the other hand, macropores can also serve

334 as growth pathways for roots, so their destruction through puddling could create 
335 another restriction. Colombi et al. (2017) showed roots of wheat, soybean and maize

336 grew preferentially towards artificially created vertical macropores $(1.25 \mathrm{~mm})$ in the

337 soil. Recently, our previous study (Fang et al., 2018) observed that macropores (>

$3380.03 \mathrm{~mm}$ ) greatly promoted rice root elongation and branching. These studies

339 indicated that macropores provided a favorable environment for root growth with

340 respect to better soil aeration and reduced penetration resistance. So far, the influence

341 of the size of macropores remains unclear. Further detailed investigations of

342 macropore-root interaction are still needed, which will be facilitated greatly by rapidly

343 growing technologies like X-ray CT. In our system, the 3D root system architecture

344 from X-ray CT images was limited to large roots due to resolution, but by using

345 smaller size samples or higher resolution obtainable with Synchrotron CT, much

346 smaller roots can be visualized (Koebernick et al., 2017), though this is at the expense

347 of considering a larger part of the total root system architecture.

348 This study was limited to rice seedlings grown in a repacked soil that was

349 carefully manipulated under controlled conditions. At field conditions, the structure of

350 paddy soil is very dynamic during the growing season due to wetting/drying cycles

351 (Mohanty et al., 2004). Two questions need to be further studied: (1) the response of

352 the puddled soil to wetting/drying cycles; and (2) their effect on rice roots considered

353 over the whole growing season, and also on the resulting rice yield. Only when these

354 questions are clearly answered can useful techniques be offered to farmers to better

355 manage their paddy fields. However, this initial study suggests decreasing puddling

356 intensity may not only save on labour and energy, but also produce favorable

357 conditions for rice root growth. 


\section{Conclusions}

360 Puddling can destroy macroaggregates and macropores, leading to an increased

361 bulk density, and decreased soil MWD, macroporosity and pore connectivity. These

362 effects are enhanced as puddling intensity increases. Puddling did not significantly

363 influence the growth of radicle or crown roots, but high intensity puddling

364 significantly reduced the length and surface area of lateral roots in the young plants

365 studied here. Further research is needed to explore more mature plants and take

366 account of the dynamic nature of soil structure over the course of a growing season.

367 Moreover, the interaction between soil structure and root system architecture of rice

368 genotypes with contrasting root traits may help identify varieties more suited to

369 China's shift towards less intensive paddy soil puddling.

370

371 Acknowledgments

372 This work was financially supported by the National Natural Science Foundation

373 of China (41471183, 41877022, 41725004, 41571130053), the National Key Research

374 and Development Program (2016YFD0300906), the Chinese National Basic Research

375 Program (2015CB150400) and the UK Natural Environmental Research Council

376 (NERC: Code: NE/N007611/1). 


\section{References}

378 Arora, V.K., Gajri, P.R., Uppal, H.S., 2006. Puddling, irrigation, and transplanting-time effects on productivity of rice-wheat system on a sandy loam soil of Punjab, India. Soil Tillage Res. 85, 212-220.

Bengough, A.G., 2012. Root elongation is restricted by axial but not by radial pressures: so what happens in field soil?. Plant Soil 360, 15-18.

Bengough, A.G., McKenzie, B.M., Hallett, P.D., Valentine, T.A., 2011. Root elongation, water stress, and mechanical impedance: a review of limiting stresses and beneficial root tip traits. J. Exp. Bot. 62, 59-68.

Ben-Noach, I., Friedman, S.P., 2018. Review and evaluation of root respiration and of natural and agricultural processes of soil aeration. Vadose Zone J. 17, 170119.

Bouman, B.A.M., Lampayan, R.M., Tuong, T.P., 2007. Water Management in Irrigated Rice: Coping with Water Scarcity. International Rice Research Institute, Los Baños, Philippines.

Cairns, J.E., Audebert, A., Townend, J., Price, A.H., Mullins, C.E., 2004. Effect of soil mechanical impedance on root growth of two rice varieties under field drought stress. Plant Soil 267, 309-318.

Chauhan, B.S., Mahajan, G., Sardana, V., Timsina, J., Jat, M.L., 2012. Productivity and Sustainability of the Rice-Wheat Cropping System in the Indo-Gangetic Plains of the Indian subcontinent: Problems, Opportunities, and Strategies. Academic Press, pp 315-369.

Colombi, T., Braun, S., Keller, T., Walter, A., 2017. Artificial macropores attract crop roots and enhance plant productivity on compacted soils. Sci. Total Environ. 574, 1283-1293.

Deng, C., Teng, X.L., Peng, X.H., Zhang, B., 2014. Effects of simulated puddling intensity and pre-drying on shrinkage capacity of a paddy soil under long-term fertilization. Soil Tillage Res. 140, 135-143.

Deurer, M., Grinev, D., Young, I., Clothier, B.E., Müller, K., 2009. The impact of soil carbon management on soil macropore structure: a comparison of two apple orchard systems in New Zealand. Eur J. Soil Sci. 60:945-955

Eickhorst, T., Tippkötter, R., 2009. Management-induced structural dynamics in paddy soils of south east China simulated in microcosms. Soil Tillage Res. 102. 168-178.

Elliott, E.T., 1986. Aggregate Structure and Carbon, Nitrogen, and Phosphorus in Native and Cultivated Soils 1. Soil Sci. Soc. Am. J. 50, 627-633. 
Fang, H., Zhou, H., Norton, G.J., Price, A.H., Raffan, A.C., Mooney, S.J., Peng, X.H., Hallett, P.D., 2018. Interaction between contrasting rice genotypes and soil physical conditions induced by hydraulic stresses typical of alternate wetting and drying irrigation of soil. Plant Soil 430, 233-243.

Helliwell, J.R., Sturrock, C.J., Grayling, K.M., Tracy, S.R., Flavel, R.J., Young, I.M., Whalley, W.R., Mooney, S.J., 2013. Applications of X-ray computed tomography for examining biophysical interactions and structural development in soil systems: a review. Eur. J. Soil Sci. 64, 279-297.

Helliwell, J.R., Sturrock, C.J., Mairhofer, S., Craigon, J., Ashton, R.W., Miller, A.J., Whalley, W.R., Mooney, S.J., 2017. The emergent rhizosphere: imaging the development of the porous architecture at the root-soil interface. Sci. Rep. 7,14875 .

Hodge, A., Berta, G., Doussan, C., Merchan, F., Crespi, M., 2009. Plant root growth, architecture and function. Plant Soil 321, 153-187.

Hovadik, J. M., \& Larue, D. K., 2007. Static characterizations of reservoirs: refining the concepts of connectivity and continuity. Petrol. Geosci. 13, 195-211.

Kirchhof, G., Priyono, S., Utomo, W.H., Adisarwanto, T., Dacanay, E.V., So, H.B., 2000. The effect of soil puddling on the soil physical properties and the growth of rice and post-rice crops. Soil Tillage Res. 56, 37-50.

Kirchhof, G., Tuong, T.P., So, H.B., 2011. Puddling: effect on soil physical properties and crops. Springer, pp 667-668.

Koebernick, N., Daly, K.R., Keyes, S.D., George, T.S., Brown, L.K., Raffan, A., Cooper, L.J., Naveed, M., Bengough, A.G., Sinclair, I., Hallett, P.D., Roose, T., 2017. High-resolution synchrotron imaging shows that root hairs influence rhizosphere soil structure formation. New Phytol. 216, 124-135.

Kolb, E., Legué, V., Bogeat-Triboulot, M.B., 2017. Physical root-soil interactions. Phys. Biol. 14, 065004.

Kukal, S.S., Aggarwal, G.C., 2003. Puddling depth and intensity effects in rice-wheat system on a sandy loam soil: I. Development of subsurface compaction. Soil Tillage Res. 72, 1-8.

Lal, R., Shukla, M.K., 2004. Principles of soil physics. CRC Press.

Lima, A.C.R., Hoogmoed, W.B., Pauletto, E.A., Pinto, L.F.S., 2009. Management systems in irrigated rice affect physical and chemical soil properties. Soil Tillage Res. 103, 92-97.

Lipiec, J., Horn, R., Pietrusiewicz, J., Siczek, A., 2012. Effects of soil compaction on root elongation and anatomy of different cereal plant species. Soil Tillage Res. 
$121,74-81$.

Liu, M., 2018. A review of Chinese rural land circulation. Rural Econ. Sci-Technol. 29, 23-28 (In Chinese).

Mohanty, M., Painuli, D.K., 2003. Land preparatory tillage effect on soil physical environment and growth and yield of rice in a Vertisol. J. Indian Soc. Soil Sci. 51, 223-228.

Mohanty, M., Painuli, D.K., Mandal, K.G., 2004. Effect of puddling intensity on temporal variation in soil physical conditions and yield of rice (Oryza sativa L.) in a Vertisol of central India. Soil Tillage Res. 76, 83-94.

Mooney, S.J., Morris, C., Berry, P.M., 2006. Visualization and quantification of the effects of cereal root lodging on three-dimensional soil macrostructure using $\mathrm{X}$-ray computed tomography. Soil Sci. 171, 706-718.

Mousavi, S.F., Yousefi-Moghadam, S., Mostafazadeh-Fard, B., Hemmat, A., Yazdani, M.R., 2009. Effect of puddling intensity on physical properties of a silty clay soil under laboratory and field conditions. Paddy Water Environ. 7, 45-54.

Rezaei, M., Tabatabaekoloor, R., Mousavi Seyedi, S.R., Aghili Nategh, N., 2012. Effects of puddling intensity on the in-situ engineering properties of paddy field soil. Aust. J. Agr. Eng. 3, 22-26.

Sharma, P.K., De Datta, S.K., 1985. Effects of puddling on soil physical properties and processes. Soil physics and rice. IRRI, Los Baños, Philippines, pp 217-234.

Singh, V.K., Dwivedi, B.S., Shukla, A.K., Meena, M.C., 2013. Effect of pre-puddling tillage and puddling intensities on soil physico-chemical properties and rice-wheat system productivity on a Typic Ustochrept of Indo-Gangetic Plains. J. Soil Water Conserv. 12, 291-300.

Tracy, S.R., Black, C.R., Roberts, J.A., McNeill, A., Davidson, R., Tester, M., Samec,

Subramanyam, D., Reddy, C.R., Reddy, D.S., 2007. Influence of puddling intensity and water-management practices on weed dynamics and yield of transplanted rice (Oryza sativa). Indian J. Agron. 52, 225-230. M., Korošak, D., Sturrock, C., Mooney, S.J., 2012a. Quantifying the effect of soil compaction on three varieties of wheat (Triticum aestivum L.) using X-ray micro computed tomography (CT). Plant Soil 353, 195-208.

Tracy, S.R., Black, C.R., Roberts, J.A., Sturrock, C., Mairhofer, S., Craigon, J., Mooney, S.J., 2012b. Quantifying the impact of soil compaction on root system architecture in tomato (Solanum lycopersicum) by X-ray micro-computed tomography. Ann. Bot. 110, 511-519.

Tracy, S.R., Roberts, J.A., Black, C.R., McNeill, A., Davidson, R., Mooney, S.J., 2010. 
The X-factor: visualizing undisturbed root architecture in soils using X-ray computed tomography. J. Exp. Bot. 61, 311-313.

Valentine, T.A., Hallett, P.D., Binnie, K., Young, M.W., Squire, G.R., Hawes, C., Bengough, A.G., 2012. Soil strength and macropore volume limit root elongation rates in many UK agricultural soils. Ann. Bot. 110, 259-270.

Wang, W., Peng, S., Liu, H., Tao, Y., Huang, J., Cui, K., Nie, L., 2017. The possibility of replacing puddled transplanted flooded rice with dry seeded rice in central China: A review. Field Crops Res. 214, 310-320.

White, R.G., Kirkegaard, J.A., 2010. The distribution and abundance of wheat roots in a dense, structured subsoil-implications for water uptake. Plant Cell Environ. 33, 133-148.

Whiteley, G.M., Dexter, A.R., 1984. Displacement of soil aggregates by elongating roots and emerging shoots of crop plants. Plant Soil 77, 131-140.

Yoshida, S., Adachi, K., 2002. Influence of puddling intensity on the water retention characteristic of clayey paddy soil. 17th WCSS, 14-21 August 2002, Thailand, Symposium No. 53, Paper No. 235, pp 1-8.

Zappala, S., Mairhofer, S., Tracy, S.R., Sturrock, C.J., Bennett, M., Pridmore, T., Mooney, S.J., 2013. Quantifying the effect of soil moisture content on segmenting root system architecture in X-ray computed tomography images. Plant Soil 370, 35-45.

Zhang, Z.B., Peng, X.H., Wang, L.L., Zhao, Q.G., Lin, H., 2013. Temporal changes in shrinkage behavior of two paddy soils under alternative flooding and drying cycles and its consequence on percolation. Geoderma 192, 12-20.

Zhang, Z.B., Zhou, H., Lin, H., Peng, X.H., 2016. Puddling intensity, sesquioxides, and soil organic carbon impacts on crack patterns of two paddy soils. Geoderma 262, 155-164. 
510 Table 1. Effects of puddling on the soil aggregate size distribution, mean weight

511 diameter (MWD), and soil bulk density. Numbers in brackets are standard error of the

512 mean. Different lowercases indicate that the means of different treatments are

513 significantly different $(P<0.05)$.

\begin{tabular}{cccccccc}
\hline \multirow{2}{*}{$\begin{array}{c}\text { Puddling } \\
\text { Intensity }\end{array}$} & \multicolumn{5}{c}{ Aggregate size distribution $\left(\mathrm{g} \mathrm{g}^{-1}\right)$} & $\begin{array}{c}\text { MWD } \\
(\mathrm{mm})\end{array}$ & $\begin{array}{c}\text { Bulk density } \\
\left(\mathrm{g} \mathrm{cm}^{-3}\right)\end{array}$ \\
\hline & $>2 \mathrm{~mm}$ & $0.25-2 \mathrm{~mm}$ & $0.05-0.25 \mathrm{~mm}$ & $<0.05 \mathrm{~mm}$ & $\Gamma$ & \\
\hline No Puddling & $0.23(0.02) \mathrm{a}$ & $0.38(0.01) \mathrm{a}$ & $0.17(0.01) \mathrm{b}$ & $0.22(0.02) \mathrm{c}$ & $1.17(0.06) \mathrm{a}$ & $0.96(0.01) \mathrm{c}$ & $0.017(0.006) \mathrm{a}$ \\
Low & $0.07(0.01) \mathrm{b}$ & $0.35(0.02) \mathrm{a}$ & $0.18(0.01) \mathrm{ab}$ & $0.40(0.02) \mathrm{b}$ & $0.57(0.01) \mathrm{b}$ & $1.06(0.01) \mathrm{b}$ & $0.008(0.002) \mathrm{ab}$ \\
High & $0.01(0.01) \mathrm{c}$ & $0.31(0.01) \mathrm{b}$ & $0.20(0.01) \mathrm{a}$ & $0.48(0.01) \mathrm{a}$ & $0.33(0.01) \mathrm{c}$ & $1.10(0.01) \mathrm{a}$ & $0.004(0.001) \mathrm{b}$ \\
\hline
\end{tabular}
514 
515 Table 2. Effects of puddling on the architecture of radicle and crown roots quantified 516 with X-ray CT imaging. Numbers in brackets are standard error of the mean. Different 517 lowercases indicate that the means of different treatments are significantly different $(P$ $518<0.05)$

\begin{tabular}{cccccc}
\hline $\begin{array}{c}\text { Puddling } \\
\text { Intensity }\end{array}$ & $\begin{array}{c}\text { Root length } \\
(\mathrm{cm})\end{array}$ & $\begin{array}{c}\text { Root diameter } \\
(\mathrm{mm})\end{array}$ & $\begin{array}{c}\text { Root surface } \\
\text { area }\left(\mathrm{cm}^{2}\right)\end{array}$ & $\begin{array}{c}\text { Root volume } \\
\left(\mathrm{cm}^{3}\right)\end{array}$ & $\begin{array}{c}\text { Root } \\
\text { tortuosity }\end{array}$ \\
\hline No Puddling & $120(8) \mathrm{a}$ & $0.35(0.03) \mathrm{a}$ & $12.3(0.8) \mathrm{a}$ & $0.12(0.01) \mathrm{a}$ & $1.22(0.01) \mathrm{a}$ \\
Low & $130(12) \mathrm{a}$ & $0.39(0.01) \mathrm{a}$ & $13.1(0.8) \mathrm{a}$ & $0.12(0.01) \mathrm{a}$ & $1.23(0.01) \mathrm{a}$ \\
High & $129(20) \mathrm{a}$ & $0.37(0.03) \mathrm{a}$ & $11.8(2.4) \mathrm{a}$ & $0.11(0.03) \mathrm{a}$ & $1.23(0.01) \mathrm{a}$ \\
\hline
\end{tabular}

519 
520 Table 3. Effects of puddling on the architecture of roots. Numbers in brackets are

521 standard error of the mean. Different lowercases indicate that the means of different

522 treatments are significantly different $(P<0.05)$.

\begin{tabular}{|c|c|c|c|c|c|c|}
\hline & $\begin{array}{l}\text { Puddling } \\
\text { Intensity }\end{array}$ & $\begin{array}{l}\text { Root length } \\
(\mathrm{cm})\end{array}$ & $\begin{array}{l}\text { Root diameter } \\
(\mathrm{mm})\end{array}$ & $\begin{array}{c}\text { Root surface } \\
\text { area }\left(\mathrm{cm}^{2}\right)\end{array}$ & $\begin{array}{l}\text { Root volume } \\
\left(\mathrm{cm}^{3}\right)\end{array}$ & $\begin{array}{c}\text { Number of } \\
\text { tips }\end{array}$ \\
\hline \multirow{3}{*}{ All roots } & No Puddling & 494(54)a & $0.19(0.01) \mathrm{b}$ & $26.1(2.6) \mathrm{a}$ & $0.30(0.01) \mathrm{a}$ & 1807(107)a \\
\hline & Low & 416(13)ab & $0.21(0.01) \mathrm{a}$ & $24.6(0.9) \mathrm{a}$ & $0.30(0.02) \mathrm{a}$ & $1628(129) a$ \\
\hline & High & $345(54) \mathrm{b}$ & $0.22(0.01) \mathrm{a}$ & $21.0(2.5) \mathrm{a}$ & $0.27(0.03) \mathrm{a}$ & $1464(112) \mathrm{a}$ \\
\hline $\begin{array}{l}\text { Radicle and } \\
\text { crown roots }\end{array}$ & No Puddling & 121(10)a & NA & 17.7(1.5)a & $0.29(0.01) \mathrm{a}$ & $31(4) a$ \\
\hline (diameter > & Low & 121(5)a & NA & $17.7(0.8) \mathrm{a}$ & $0.28(0.02) \mathrm{a}$ & $38(5) \mathrm{a}$ \\
\hline $0.2 \mathrm{~mm})$ & High & 104(11)a & NA & $15.8(1.5) \mathrm{a}$ & $0.26(0.03) \mathrm{a}$ & $35(5) \mathrm{a}$ \\
\hline $\begin{array}{c}\text { Lateral } \\
\text { roots }\end{array}$ & No Puddling & 373(46)a & NA & $8.4(1.2) \mathrm{a}$ & $0.02(0.003) \mathrm{a}$ & 1776(106)a \\
\hline (diameter < & Low & 295(10)ab & NA & $7.0(0.5) \mathrm{ab}$ & $0.02(0.002) \mathrm{a}$ & $1590(127) \mathrm{a}$ \\
\hline $0.2 \mathrm{~mm})$ & High & $241(43) b$ & NA & $5.2(1.0) \mathrm{b}$ & $0.01(0.003) \mathrm{a}$ & $1429(115) \mathrm{a}$ \\
\hline
\end{tabular}




\section{Figure captions}

525 Figure 1. Vertical images of soil cores from different puddling intensities. Dark color 526 indicates pore space, light gray indicates soil matrix.

528 Figure 2. Three-dimensional images of soil cores from different puddling intensities.

529 Light color indicates pores, dark color indicates soil matrix. Sample size length is 21

$530 \mathrm{~mm}$.

531

532 Figure 3. Effects of puddling intensity on the soil pore size distribution (a) and

533 cumulative pore size distribution (b) quantified using X-ray CT imaging. The shaded 534 areas are the standard error of the mean.

535

536 Figure 4. Representative three-dimensional root architecture acquired with X-ray CT

537 imaging from different puddling intensities.

538

539 Figure 5. Representative two-dimensional root images from different puddling 540 intensities. 


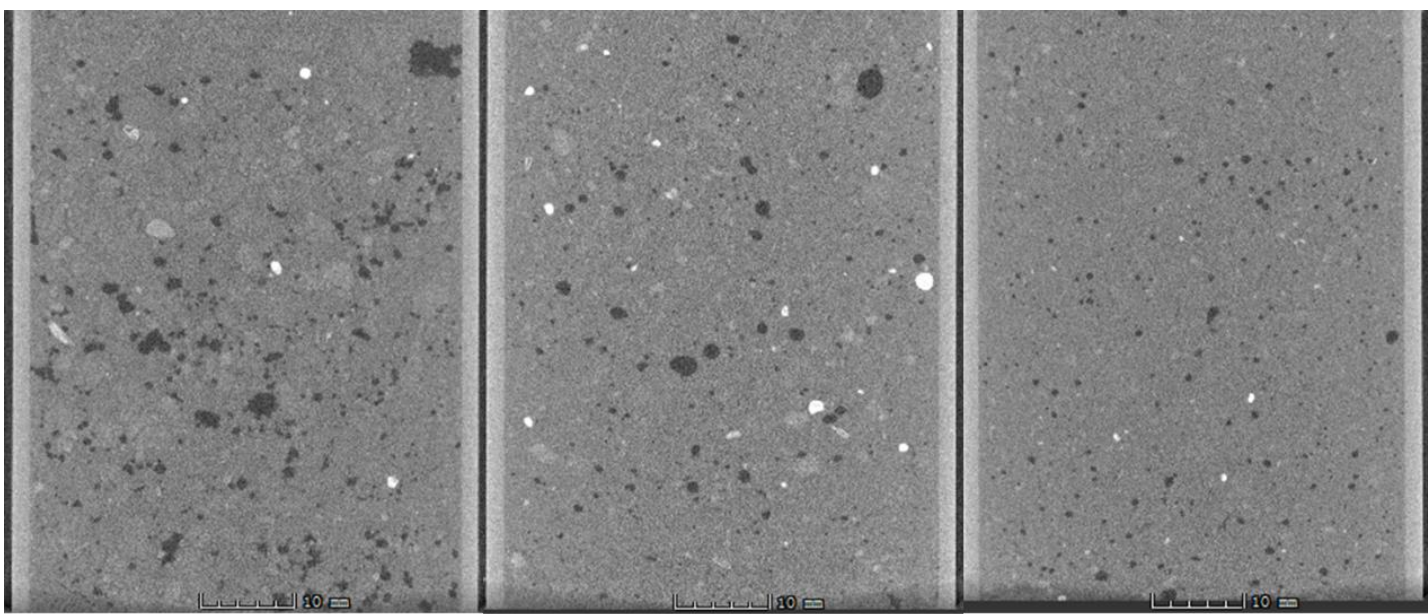

No Puddling

Low

High

543 Figure 1. Vertical images of soil cores from different puddling intensities. Dark color 544 indicates pore space, light gray indicates soil matrix. 


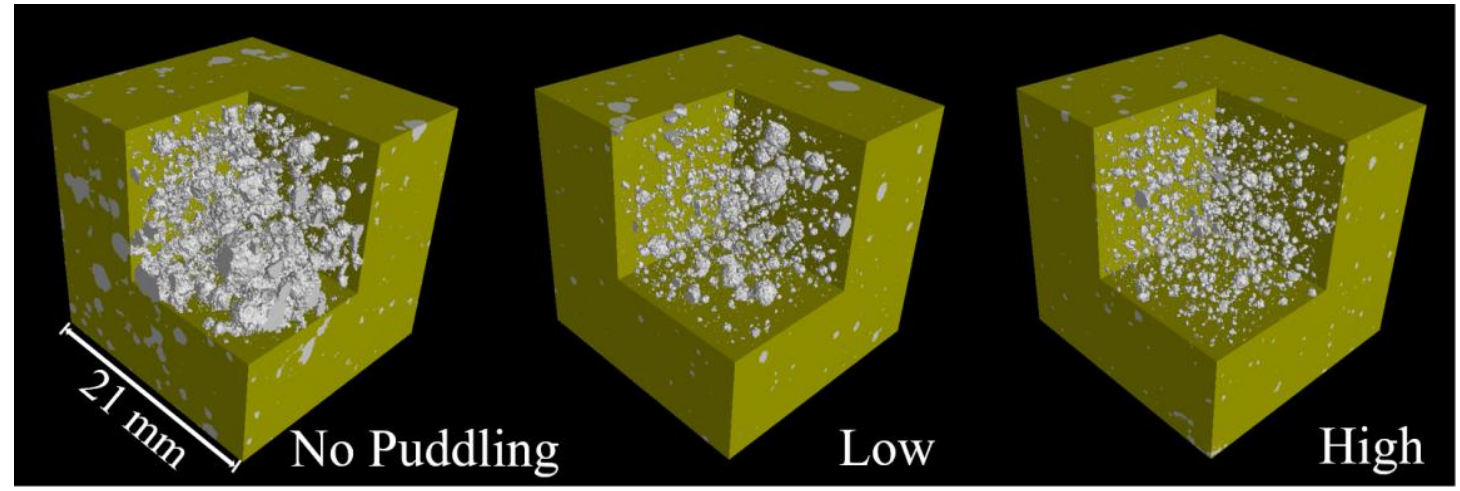

547 Figure 2. Three-dimensional images of soil cores from different puddling intensities.

548 White color indicates pores, olive green color indicates soil matrix. Sample size 549 length is $21 \mathrm{~mm}$. 


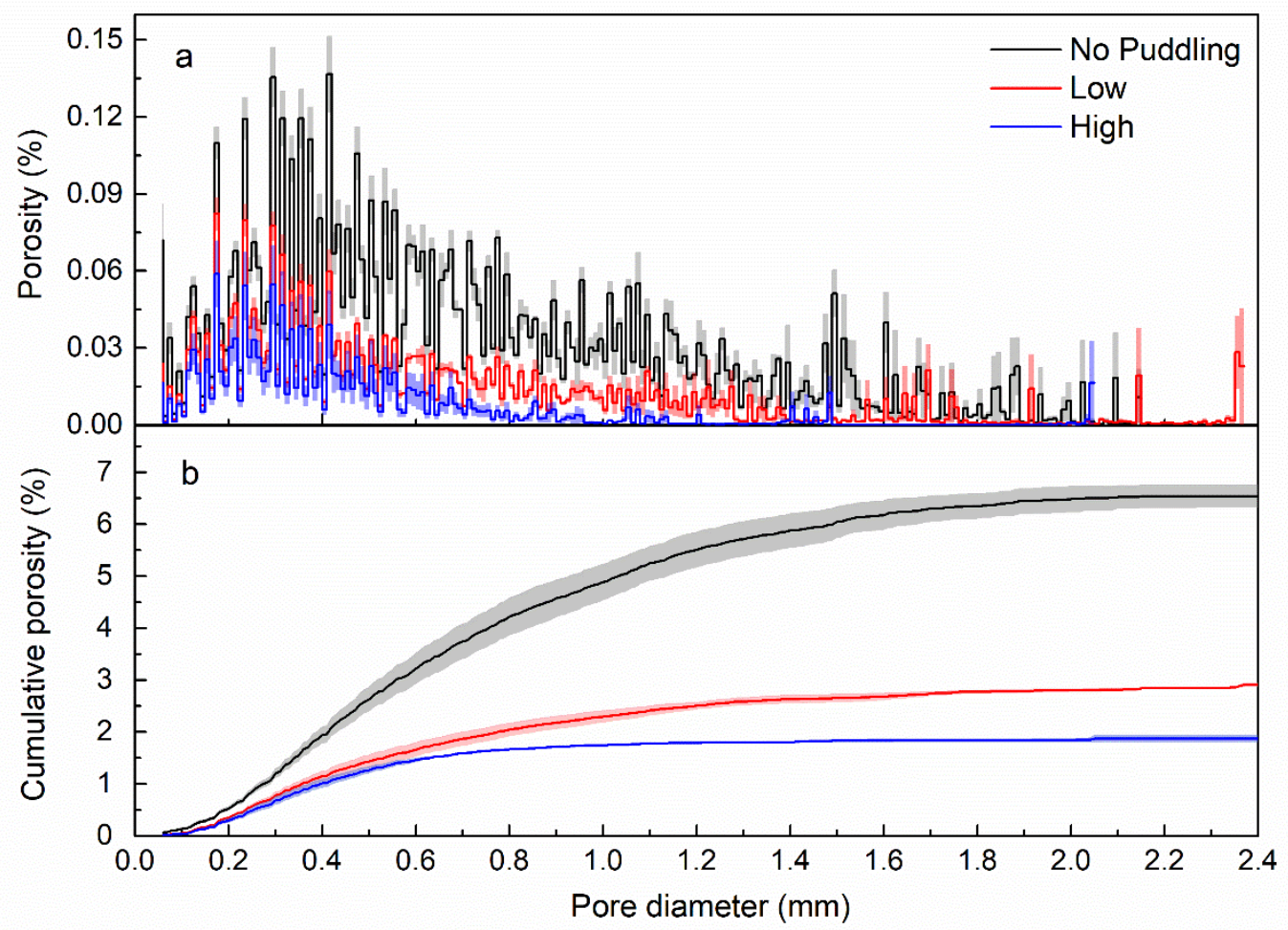

551 Figure 3. Effects of puddling intensity on the soil pore size distribution (a) and 552 cumulative pore size distribution (b) quantified using X-ray CT imaging. The shaded 553 areas are the standard error of the mean. 


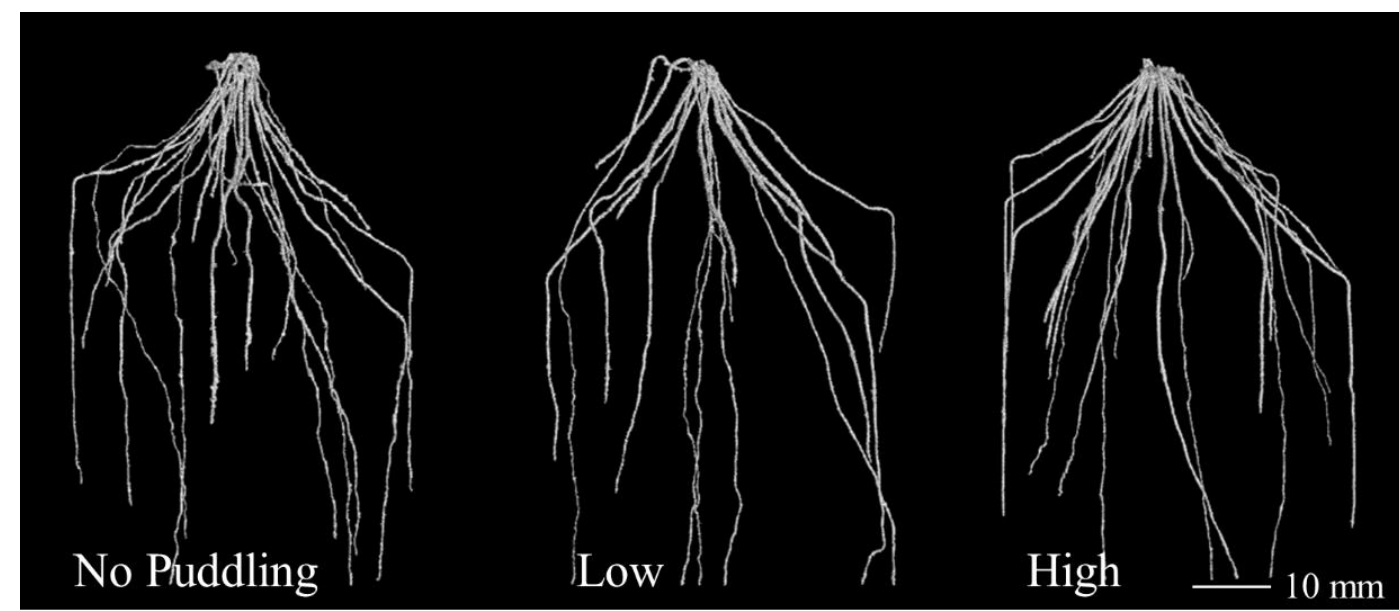

555 Figure 4. Representative three-dimensional root architecture acquired with X-ray CT 556 imaging from different puddling intensities. Lateral roots were not observable due to 557 the resolution. 


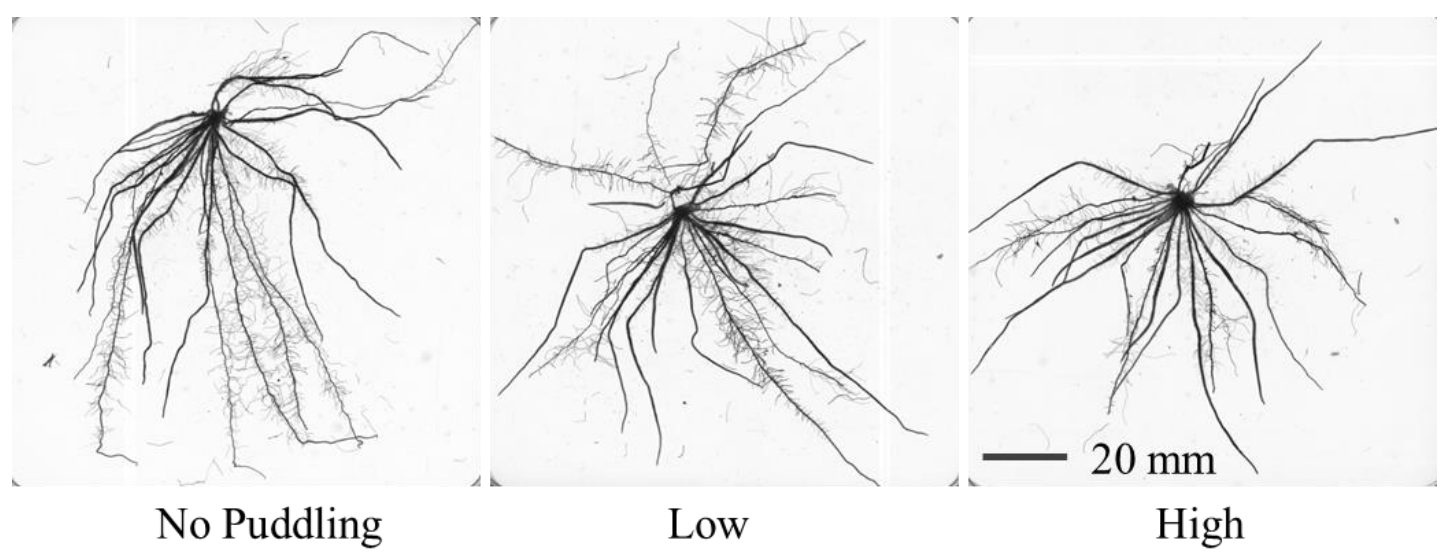

561 Figure 5. Representative two-dimensional root images from different puddling 562 intensities.

563 